\title{
Association between maternal race and the use of assisted reproductive technology in the USA
}

\author{
Dandison Nat Ebeh ${ }^{1}$ (D) Shayesteh Jahanfar ${ }^{1}$
}

Accepted: 8 March 2021 / Published online: 18 March 2021

(C) The Author(s), under exclusive licence to Springer Nature Switzerland AG 2021

\begin{abstract}
Despite advances in the field of infertility medicine and its availability, disparities affect the accessibility status worldwide. Racial disparities could potentially affect the utilization of assisted reproductive technology (ART). We aimed at studying the association between maternal race and the use of ART treatment in the USA. We analyzed a secondary dataset (2017 Natality) obtained from the Centers for Disease Control and Prevention. This cross-sectional study acquired information on maternal race as well as ART utilization from women living within the reporting States and US territories. We analyzed the data using descriptive, bivariate, and regression analysis. A total of 3,864,754 live births out of 325,719,178 US races and origin populations were reported for the 2017 review year. A total of 42,846 women who had a live birth reported utilization of ART out of 67,554 respondents. The Chi-square test showed a statistically significant association between maternal race and the use of ART treatment, $p$ value 0.01 . Unadjusted regression odds of the utilization of ART at $95 \%$ confidence interval (CI) was $87 \%$ higher among non-Hispanic Asian women as compared to the non-Hispanic White. We also found higher odds for maternal age 35-54 years 2.41 (95\% CI 2.34-2.49), maternal education (above college degree) 1.36 (95\% CI 1.31-1.42), and non-smoking status 2.44 (95\% CI 2.02-2.94). Compared to the non-Hispanic white race, the adjusted regression odds were lower for all other racial/ ethnic minorities except for the non-Hispanic Asian 63\% (95\% CI 1.09-2.44) and non-Hispanic mixed race 59\% (95\% CI 0.813.10) subgroups. The study finds the utilization of ART in the USA to be associated with maternal race.
\end{abstract}

Keywords Association $\cdot$ Maternal race $\cdot$ Assisted reproductive technology $\cdot$ USA

\section{Introduction}

Despite advances in the field of infertility medicine and its availability, disparities are said to exist in the utilization of infertility services globally ([1]; Ombelet [2]; Shapiro et al. [3]; de Mouzon et al. [4]; [5]). In the USA, racial/ethnic disparities are reported to constitute a major influence on both the utilization and outcome of infertility services (Quinn and Fujimoto [6]; Dieke et al. [7]; [8]). This is regardless of the success story of the first US conceived infant born in 1981, which was achieved through assisted reproductive technology (Centers for Disease Control and Prevention [9, 10]). An improved form of fertility treatments in which male and female

This article is part of the Topical Collection on Medicine

Dandison Nat Ebeh

ebeh1dn@cmich.edu; https://www.cmich.edu

1 MPH Program, Central Michigan University, Health Sciences Building, 2242, Mount Pleasant, MI 48859, USA gametes or embryos are processed in the laboratory (commonly an in vitro fertilization [IVF] and related procedures) to achieve procreation. The use of ART and the number of fertility clinics providing ART services continue to surge across the country; sadly, racial disparity continues to militate against equal access and delivery (Adamson et al. (2006, as cited in Reefhuis et al. (2008)) [11]. According to the CDC [9, 10], access to these infertility services is an "emerging public health priority," for which, in 1995, "CDC began collecting data on ART procedures performed in fertility clinics in the United States as mandated by the Fertility Clinic Success Rate and Certification Act of 1992 (FCSRCA) (Public Law 102493 [October 24, 1992])." These reports are obtained from 52 reporting areas (the 50 states, Puerto Rico, and the District of Columbia) $[9,10]$. Reflecting of total information on reports from "present multiple measures for successful ART intervention, (including the percentage of ART procedures and transfers that resulted in pregnancies), live-birth deliveries, singleton live-birth deliveries, and multiple live-birth deliveries."

Although ART helps millions of American achieve pregnancy, the reported trend shows states and racial disparities 
with the latest in 2016, revealing a total of 197,706 ART procedures (range: 162 in Wyoming to 24,030 in California); an intent to transfer at least one embryo was performed in 463 US fertility clinics and reported to CDC $[9,10]$. These procedures resulted in 65,964 live birth deliveries (range: 57 in Puerto Rico to 8638 in California) and 76,892 infants born (range: 74 in Alaska to 9885 in California). Nationally, the number of ART procedures performed per 1 million women of reproductive age (15-44 years), a proxy measure of the ART use rate, was 3075. ART use rates exceeded the national rate in 14 reporting states/areas (Connecticut, Delaware, the District of Columbia, Hawaii, Illinois, Maryland, Massachusetts, New Hampshire, New Jersey, New York, Pennsylvania, Rhode Island, Utah, and Virginia). ART use exceeded 1.5 times the national rate in nine states, including three (Illinois, Massachusetts, and New Jersey) that also had comprehensive mandated health insurance coverage for ART procedures (i.e., coverage for at least four oocyte retrievals)," [9, 10].

Several types of research have affirmed this position ([12] cited by [3]) with individuals of racial/ethnic minority groups, generally demonstrating poorer ART utilization and health outcomes than non-Hispanic white patients. Humphries et al. [13] in a systemic review concluded that current evidence points to race and ethnicity as a strong predictor of poorer clinical pregnancy rates and/or outcomes after ART treatment. This was from a review of twenty-four studies, where five (5) US registry-based studies showed that black, Hispanic, and Asian women had a lower ART procedure success when compared to non-Hispanic white racial women. These differences also persist even when adjusting for disease (infertility) severity, age, insurance coverage, marital status, income, and educational status (Nelson (2002; as cited in [3])). Race/ethnicity, therefore, seems to be an important predictor of ART utilization and outcome. However, which race-associated factors are responsible for these differences in ART utilization as well as outcomes has remained controversial in many studies. Some authors have suggested genetic predisposition difference in the distribution of FMR1 gene mutations [3] and socioeconomic and cultural differences (Seifer et al., (2010) (Wellons, et al. (2002), Seifer et al. [14], and Feinberg et al. [15]).

Prevention of reproductive health disparities affecting utilization of ART requires "monitoring race-specific infertility prevalence, treatment patterns, and related risk factors to identify, guide, implement and monitor effective public health action strategies to safeguard reproductive health" $[9,10]$ (World Health Organization [16]). Given the differential utilization or outcome of a specific service in healthcare delivery or practice like ART, the service suggests a barrier to infertility care which in turn populates reproductive health disparities among underserved populations [17]. Then, there is the need to establish/ elucidate this association and inform literature, thus improving practice and utilization in the USA as well as globally.
This study seeks to address this need by analyzing a secondary dataset using a cross-sectional design. The objective is to study the association of maternal race on the use of ART (IVF) in the USA in a nationally representative sample, as reported in the 2017 CDC Natality Public Use file, with a view to describe this association.

\section{Methods}

\section{Data}

Secondary datasets were obtained from the Centers for Disease Control and Prevention 2017 Natality Public Use file. A crosssectional observation of the racial distribution of ART use among a total US population of $325,719,178$ of all races and ethnic origin was made for the reported year. A total of 67,554 responded to questionnaire question on ART, and 3,864,754 birth record counts were reported in the review by the 50 states, including the district of Columbia and US Territories. A total of 48 states and the District of Columbia (excluding South Carolina and Tennessee) reported information on the type of infertility treatment used, representing 96.4 percent of 2017 births.

This cross-sectional study acquired sociodemographic information and clinical/obstetrics and gynecological history maternal race (explanatory variables) as well as infertility treatment utilization ART (outcome variable) from women living within this reporting States and US territories.

\section{Participants}

A secondary dataset of 67,554 respondents (who had responded to the questionnaire question section on ART use) of the women (3,864,754 reported birth records) who fell within the reporting states and US territories constituted participants for the study. Women who received natal care outside the reporting coverage were not reported in the file and thus were ineligible for the study. Male partners were also excluded to eliminate duplication of responses.

\section{Study variables}

The independent variable for the study was the race, and this was obtained from a recorded reported mother's race of a seven categories consisting of non-Hispanic White (only), nonHispanic Black (only), non-Hispanic American Indians and Alaska Native (AIAN) only, non-Hispanic Asian (only), nonHispanic Native Hawaiian or Other Pacific Islander (NHOPI) only, non-Hispanic (Mixed race), and Hispanic and also two ethnic-based subcategories of non-Hispanic (all races) and Hispanic statuses.

The dependent variable was the use of ART entailing primarily in vitro fertilization (IVF); other methods include gamete 
intrafallopian transfer (GIFT), and zygote intrafallopian transfer (ZIFT). This outcome (binary) of interest was obtained from the self-reported use of ART as noted from the report, noted as the reporting flag.

Several other variables were added during the analysis of Race and ART use to adjust for potential covariate and confounding effects. These cofounders include sociodemographic variables (mother's age (under 35 years and 35 to 54 years), previous cesarean (yes/no), fertility enhancing drug (yes/no), payment method (Medicaid, private insurance, self-pay, others), and educational levels) and obstetric and gynecological/clinical variables (gonorrhea infection (yes, no), syphilis infection (yes, no), chlamydia infection (yes, no), pre-pregnancy diabetes (yes/no), previous cesarean (yes/ no), and fertility enhancing drug (yes/no).

These final confounding variables for the adjusted models were selected after performing a 2-stage process. First, a series of statistical tests were performed to assess frequency distribution and then checked for characteristics of a relationship with ART use. Confounders that were significantly $(p<0.05)$ associated with either ART use were considered in the next stage, involving binary logistic regression analysis for association correlation.

The list of potential confounders was further reduced using multivariate logistic regression modeling and a backward elimination stepwise regression approach, keeping only those variables that were significant at $p<0.05$.

Giving the large sample size $(67,554$ ART use respondents of the total race population from all races $N=325,719,178$, live birth record $n=3,864,754$, and having 48 out of 50 reporting state), statistical analysis was powerful enough to evaluate the association between variables.

\section{Statistical analysis}

This was carried out using IBM SPSS Statistics for Windows, version 26 (IBM Corp., Armonk, N.Y., USA). Tests included descriptive statistics, Chi-square tests for categorical variables, and binary logistic regression analysis. Both unadjusted (OR) and adjusted (AOR) odds ratios with $95 \%$ confidence intervals were calculated to approximate associations with variables having a $p$ value of less than 0.01 . OR and AOR were extrapolated and checked for significance and variation between unadjusted and adjusted.

\section{Results}

\section{Descriptive analysis}

From the dataset, 3,864,754 live births were reported out of a total US population of $325,719,178$ of all races and origin. A total number of 42,846 women reported use of ART treatment out of 67,554 respondents (study sample). Table 1 demonstrates
Table 1 Frequency distribution of data from women who used ART from Natality Public Use dataset, CDC, 2017

\begin{tabular}{|c|c|}
\hline Variables & Frequency $(\%)$ \\
\hline \multicolumn{2}{|l|}{ Assisted reproductive technology } \\
\hline Yes & $42,846(63.4)$ \\
\hline No & $24,708(36.6)$ \\
\hline \multicolumn{2}{|l|}{ - Sociodemographic } \\
\hline \multicolumn{2}{|l|}{ Race (independent variable) } \\
\hline \multicolumn{2}{|l|}{ Race } \\
\hline Non-Hispanic White (only) & $1,993,312(52.0)$ \\
\hline Non-Hispanic Black (only) & $561,297(14.6)$ \\
\hline Non-Hispanic AIAN* (only) & $29,967(0.8)$ \\
\hline Non-Hispanic Asian (only) & $249,616(6.5)$ \\
\hline Non-Hispanic NHOPI** (only) & $9436(0.2)$ \\
\hline Non-Hispanic (Mixed race) & $82,455(2.2)$ \\
\hline Hispanic & $905,998(23.6)$ \\
\hline \multicolumn{2}{|l|}{ Racial/ethnic origin subcategory } \\
\hline Non-Hispanic (all race) & $2,926,083(76.4)$ \\
\hline Hispanic & $905,998(23.6)$ \\
\hline \multicolumn{2}{|l|}{ Mother's age } \\
\hline Under 35 years & $3,183,939(82.4)$ \\
\hline 35 to 54 years & $3,658,660(17.6)$ \\
\hline \multicolumn{2}{|l|}{ Marital status } \\
\hline Married & $2,032,203(59.9)$ \\
\hline Unmarried & $1,359,731(40.1)$ \\
\hline \multicolumn{2}{|l|}{ Educational status } \\
\hline Below college degree & $2,262,739(59.3)$ \\
\hline Above college degree & $1,552,228(40.7)$ \\
\hline \multicolumn{2}{|l|}{ - Payment method } \\
\hline Medicaid & $1,648,323(42.9)$ \\
\hline Private insurance & $1,882,268(49.0)$ \\
\hline Self-pay & $163,242(4.2)$ \\
\hline Others & $\cdot 147,445(3.8)$ \\
\hline \multicolumn{2}{|c|}{ - Obstetric and gynecological/clinical variables } \\
\hline \multicolumn{2}{|l|}{ Gestation } \\
\hline Under 37 weeks & $448,989(11.6)$ \\
\hline 37 weeks over & 3,412,937 (88.4) \\
\hline \multicolumn{2}{|l|}{ Gonorrhea infection } \\
\hline Yes & $11,336(0.3)$ \\
\hline No & $3,843,319(99.7)$ \\
\hline \multicolumn{2}{|l|}{ Syphilis infection } \\
\hline Yes & $3898(0.1)$ \\
\hline No & $3,850,757(99.1)$ \\
\hline \multicolumn{2}{|l|}{ Chlamydia infection } \\
\hline Yes & $70,580(1.8)$ \\
\hline No & $3,784,075(98.2)$ \\
\hline \multicolumn{2}{|l|}{ Pre-pregnancy diabetes } \\
\hline Yes & $35,365(0.9)$ \\
\hline No & $3,825,603(99.1)$ \\
\hline \multicolumn{2}{|l|}{ Fertility enhancing drug } \\
\hline Yes & $30,560(45.2)$ \\
\hline
\end{tabular}


Table 1 (continued)

\begin{tabular}{ll}
\hline Variables & Frequency (\%) \\
\hline No & $36,994(54.8)$ \\
Previous cesarean & \\
Yes & $598,525(15.5)$ \\
No & $3,262,443(84.5)$ \\
Smoking status & \\
Yes & $264,975(6.9)$ \\
No & $3,845,913(93.1)$ \\
\hline
\end{tabular}

Total race population $N=325,719,178$, total live birth $n=3,864,754$. Total ART performed: 67,554

$A I A N^{*}$ American Indian and Alaska Native

NHOPI** Native Hawaiian or Other Pacific Islander

the overall frequency distribution for our independent variable, confounders, as well as for those who had used ART and those who did not. A review of Table 1 shows that those who responded "YES" to ART were $63.4 \%$ and "NO" were $36.6 \%$. The independent variable maternal race had racial/ ethnic frequency distribution of non-Hispanic white only $52.0 \%$, non-Hispanic Black only $14.6 \%$, non-Hispanic AIAN only $0.8 \%$, non-Hispanic Asian only $6.5 \%$, non-Hispanic NHOPI $0.2 \%$, non-Hispanic (mixed race) $2.2 \%$, and Hispanic $23.1 \%$ respectively, and also, a dichotomous ethnic distribution of non-Hispanic (all races) $76.4 \%$ and Hispanic $23.6 \%$. The rest of the variables (confounders), mother's age has its age distribution to be $82.4 \%$ (under 35 years) and $17.6 \%$ (35-54 years); marital status having $59.9 \%$ married and $40.1 \%$ unmarried; gestation has $11.6 \%$ under 37 weeks and $88.4 \%$ over 37 weeks; payment method having $49 \%$ as private insurance, $42.9 \%$ Medicaid, $4.2 . \%$ self-paid, and $3.8 \%$ others; Gonorrheal, syphilis and chlamydia infections were seen to have a low prevalence of $0.3 \%, 0.1 \%, 1.8 \%$ respectively; Prepregnancy Diabetes $(0.9 \%)$. Bivariate analysis using the Chisquare test as displayed in Table 2 showed a statistically significant association between each of the explanatory variables and the outcome variable. Vis-a-vis maternal race, mother's age, marital status, gestation, payment method, educational status, fertility enhancing drug, previous cesarean section, and smoking status all have a $p$ value of 0.01 each, respectively. Gonorrheal (0.43), syphilis (0.31), and chlamydia infections (0.93) were seen not to have significant $p$ values; Also, was Pre-pregnancy Diabetes having a $p$ value of 0.04 .

\section{Regression analysis}

\section{Unadjusted regression}

Table 3 presents the odds of having an ART treatment based on the independent variables and confounders examined (vis-
Table 2 Association between race and the use of assisted reproductive technology in the USA

\begin{tabular}{|c|c|c|c|}
\hline Variables & ART (yes) & ART (no) & $\begin{array}{l}p \\
\text { Value }\end{array}$ \\
\hline \multicolumn{4}{|l|}{ Race (independent variable) } \\
\hline \multicolumn{4}{|l|}{ Race } \\
\hline $\begin{array}{l}\text { Non-Hispanic White (only) } \\
\text { Non-Hispanic Black (only) }\end{array}$ & $\begin{array}{l}29,512(61.2) \\
2168(65.1)\end{array}$ & $\begin{array}{l}18,709(38.8) \\
1164(34.9)\end{array}$ & 0.01 \\
\hline Non-Hispanic AIAN* (only) & $52(46.8)$ & $59(53.2)$ & \\
\hline Non-Hispanic Asian (only) & $5442(73.5)$ & $1967(26.5)$ & \\
\hline $\begin{array}{l}\text { Non-Hispanic NHOPI** } \\
\text { (only) }\end{array}$ & $33(63.3)$ & $20(37.7)$ & \\
\hline Non-Hispanic (Mixed race) & $691(65.0)$ & $372(35.0)$ & \\
\hline Hispanic & $3697(62.3)$ & $2241(37.7)$ & \\
\hline \multicolumn{4}{|l|}{ Racial/ethnic origin subcategory } \\
\hline $\begin{array}{r}\text { Non-Hispanic (all race) } \\
\text { Hispanic }\end{array}$ & $\begin{array}{l}37,898(63.0) \\
3697(62.3)\end{array}$ & $\begin{array}{l}22,291(37.0) \\
2241(37.7)\end{array}$ & \\
\hline \multicolumn{4}{|c|}{ Confounders (sociodemographic variables) } \\
\hline \multicolumn{4}{|c|}{ Mother's age } \\
\hline $\begin{array}{l}\text { Under } 35 \text { years } \\
35 \text { to } 54 \text { years }\end{array}$ & $\begin{array}{l}18,803(53.8) \\
24,043(73.8)\end{array}$ & $\begin{array}{l}16,153(46.2) \\
8555(26.2)\end{array}$ & 0.01 \\
\hline \multicolumn{4}{|l|}{ Marital status } \\
\hline Married & $34,114(61.2)$ & $\begin{array}{l}21,659 \\
(38.8)) \\
1616(36.5)\end{array}$ & 0.01 \\
\hline \multicolumn{4}{|l|}{ Educational status } \\
\hline $\begin{array}{l}\text { Below college degree } \\
\text { Above college degree }\end{array}$ & $\begin{array}{l}7188(56.9) \\
34,254(64.3)\end{array}$ & $\begin{array}{l}5454(43.1) \\
19,049(35.7)\end{array}$ & 0.01 \\
\hline \multicolumn{4}{|l|}{ Payment method } \\
\hline $\begin{array}{l}\text { Medicaid } \\
\text { Private insurance }\end{array}$ & $\begin{array}{l}2291(55.9) \\
38,730(64.1)\end{array}$ & $\begin{array}{l}1808(44.1) \\
21,695(35.9)\end{array}$ & 0.01 \\
\hline Self-pay & $833(65.4)$ & $441(34.6)$ & \\
\hline Other & $855(55.2)$ & $694(44.8)$ & \\
\hline
\end{tabular}

Obstetric and gynecological/clinical variables

Gestation

Under 37 weeks

37 weeks over

$11,354(66.6) \quad 5704(33.4) \quad 0.01$

Gonorrhea infection

Yes

No

$11(73.3) \quad 4(26.7)$

0.43

$42,796(63.4) \quad 24,683(36.6)$

Syphilis infection

Yes

$10(76.9) \quad 3(23.1) \quad 0.31$

No

$42,797(63.4) \quad 24,684(36.6)$

Chlamydia infection

Yes

$95(63.8) \quad 54(36.2) \quad 0.93$

No

42,712(63.4) 24,633 (36.6)

Pre-pregnancy diabetes

Yes

$448(59.8) \quad 301(40.2) \quad 0.04$

No

$42,398(63.5) \quad 24,407(36.5)$

Fertility enhancing drug

Yes

$5852(19.1) \quad 24708(80.9) \quad 0.01$

No

$36,994 \quad 0(0.0)$

(100.0)

Previous cesarean

$\begin{array}{llll}\text { Yes } & \text { 5960(66.5) } & \text { 3005(33.5) } & 0.01\end{array}$ 
Table 2 (continued)

\begin{tabular}{llll}
\hline Variables & ART (yes) & ART (no) & $p$ \\
& & & Value \\
\hline No & $36,886(63.0)$ & $21,703(37.0)$ & \\
Smoking status & & & \\
Yes & $189(41.7)$ & $264(58.3)$ & 0.01 \\
No & $42,574(63.6)$ & $24,399(36.4)$ & \\
\hline
\end{tabular}

Chi-square test statistical analysis result of race (independent variable) confounders variables and ART use (dependent variable) (Natality Public Use file, CDC, 2017). Total race population $N=325,719,178$, total live birth $(n)=3,864,754$, total ART performed: 67,554

$A I A N^{*}$ American Indian and Alaska Native

NHOPI* Native Hawaiian or Other Pacific Islander

a-vis mother's race (independent variable), sociodemographic variables (mother's age, marital status, educational status, payment methods), and obstetric and gynecological/clinical variables (gestation, previous cesarean, smoking status)).
The unadjusted odds ratios at $95 \% \mathrm{CI}$ for the association between maternal race and ART use was $87 \%$ higher among non-Hispanic Asian (only) when compared to the nonHispanic white race (only). It was $141 \%$ for mothers of age category (35 to 54 years), $11 \%$ for the unmarried, $36 \%$ for those with a college degree, and $144 \%$ for those who smoke. The unadjusted odds ratios at $95 \% \mathrm{CI}$ for the association between maternal race and ART use was lower for non-Hispanic AIAN only ( $11 \%$ less likely), non-Hispanic NHOPI only (40\% less likely), and Hispanic ( $11 \%$ less likely). However, non-Hispanic (mixed race) $1.00(0.57-1.75) 95 \% \mathrm{CI}$ and nonHispanic Black only $1.05(0.99-1.06) 95 \%$ CI had an approximately equal association (ART use) when compared to the non-Hispanic white (only).

\section{Adjusted regression}

When adjusted for the confounding variables, the OR for this relationship was of the higher side for many of the variables.

Table 3 Association between race and the use of assisted reproductive technology in the USA

\begin{tabular}{|c|c|c|}
\hline Variables & Unadjusted odd ratio AOR $(95 \% \mathrm{CI})$ & Adjusted odd ratio AOR $(95 \% \mathrm{CI})$ \\
\hline \multicolumn{3}{|l|}{ Race } \\
\hline Non-Hispanic White (only) & 1 & 1 \\
\hline Non-Hispanic Black (only) & $1.05(0.99-1.06)$ & $0.99(0.93-1.05)$ \\
\hline Non-Hispanic AIAN* (only) & $0.89(0.81-0.97)$ & $0.84(0.76-0.92)$ \\
\hline Non-Hispanic Asian (only) & $1.87(1.28-2.73)$ & $1.63(1.09-2.44)$ \\
\hline Non-Hispanic NHOPI** (only) & $0.60(0.55-0.64)$ & $0.67(0.61-0.72)$ \\
\hline Non-Hispanic (mixed race) & $1.00(0.57-1.75)$ & $1.59(0.81-3.10)$ \\
\hline Hispanic & $0.89(0.78-1.02)$ & $0.85(0.73-0.99)$ \\
\hline \multicolumn{3}{|l|}{ Confounders } \\
\hline \multicolumn{3}{|l|}{ Mother's age } \\
\hline Under 35 years & 1 & 1 \\
\hline 35 to 54 years & $2.41(2.34-2.49)$ & $2.23(2.15-2.31)$ \\
\hline \multicolumn{3}{|l|}{ Marital status } \\
\hline Married & 1 & 1 \\
\hline Unmarried & $1.11(1.04-1.18)$ & $1.04(0.97-1.11)$ \\
\hline \multicolumn{3}{|l|}{ Educational status } \\
\hline Below college degree & 1 & 1 \\
\hline Above college degree & $1.36(1.31-1.42)$ & $1.16(1.12-1.22)$ \\
\hline \multicolumn{3}{|l|}{ Gestation } \\
\hline Under 37 weeks & 1 & 1 \\
\hline 37 weeks over & $0.83(0.80-0.86)$ & $0.83(0.79-0.86)$ \\
\hline \multicolumn{3}{|l|}{ Payment method } \\
\hline Medicaid & 1 & 1 \\
\hline Private insurance & $0.97(0.86-1.09)$ & $0.92(0.81-1.05)$ \\
\hline Self-pay & $0.69(0.62-0.76)$ & $0.73(0.66-0.82)$ \\
\hline Other & $0.65(0.56-0.76)$ & $0.96(0.81-1.14)$ \\
\hline \multicolumn{3}{|l|}{ Previous cesarean } \\
\hline Yes & 1 & 1 \\
\hline No & $0.86(0.82-0.90)$ & $0.97(0.92-1.02)$ \\
\hline \multicolumn{3}{|l|}{ Smoking status } \\
\hline Yes & 1 & 1 \\
\hline No & $2.44(2.02-2.94)$ & $1.89(1.54-2.31)$ \\
\hline
\end{tabular}

Binary logistic regression result of maternal race (independent variable) confounders variables and ART use (dependent variable) (Natality Public Use file, CDC, 2017). Total race population $N=325,719,178$, total live birth $(n)=3,864,754$. Total ART performed: 67,554

AIAN* American Indian and Alaska Native

NHOPI** Native Hawaiian or Other Pacific Islander 
The odds of ART were $63 \%$ higher among non-Hispanic Asian (only) (95\% CI 1.092 .44 ) and 59\% among nonHispanic (mixed race) $(95 \%$ CI $0.81-3.10)$ compared to non-Hispanic white. The correlation between the variables in the adjusted model was lower (less likely) for all the other race subcategories, $1 \%$ non-Hispanic Black (95\% CI 0.93-1.05), $16 \%$ non-Hispanic AIAN (95\% CI $0.76-0.97$ ), 33\% nonHispanic NHOPI (95\% CI 0.61-0.72), and 15\% Hispanic (95\% CI 0.73-0.99) statuses. These results suggest that the probability of having an ART done is high if the individual is non-Hispanic white, non-Hispanic Asian, and non-Hispanic (mixed race), but less if they are non-Hispanic Black, nonHispanic AIAN, non-Hispanic NHOPI, and Hispanic racial/ ethnic statuses. The odds of having an ART treatment is also elevated if the individual is of the age from 35 to 54 years $123 \%$ (95\% CI 2.15-2.31), does not smoke $89 \%$ (95\% CI 1.54-2.31), has at least a college degree $16 \%$ (95\% CI 1.121.22 ), or unmarried $4 \%$ (95\% CI $0.97-1.11$ ).

All confounding variables reflected significant values. Adjustment of mother's age categories (35-54 years) shows OR decrease of 0.18 (2.41-2.23). Educational status above college degree shows 0.20 OR increase (1.36-1.16). Nonsmoking status showed 0.55 (2.44-1.89) OR decrease.

Unmarried marital status shows a 0.07 (1.11-1.04) OR decrease, while all the following shows an increment $\mathrm{OR}$ at 95\% CI: previous cesarean $0.11(0.97-0.86)$ and payment method (self-pay $0.04(0.73-0.69)$ and other $0.31(0.96-$ $0.65)$, the exception here being private insurance, having a 0.05 decrease (0.97-0.92) on adjustment).

\section{Discussion}

The disparity in access to healthcare continues to pose a challenge to equitable healthcare delivery. If this is seen reflected in ART treatment delivery, its dose calls for concern as it further deepened an already established inequality. Although a zero absence of barrier in a healthcare delivery setting may be practically non-realizable, the global concern is equal access to health for all, irrespective of sociodemographic background. According to [18]; as cited in [19]), the fertility rate in the USA has decreased to the lowest point, as at the first quarter of 2016 having 59.8 babies for every 1000 women of ages 15 to 44 , a near half the rate of the baby boom peak in the 1950s. Hamilton et al. [20] in their second annual series vital statistics rapid release statistic carried out on US birth data of 2017 (based on a $99.93 \%$ of birth record by maternal age and race/Hispanic origin) report a downward 2\% ( $3,853,472$ total births) from that of 2016, representing the lowest number in 30 years. This federal data statistics trend depicts an unmistakable sequela of women delaying motherhood mainly because of sociodemographic reasons (maternal race/ethnicity, age, educational status, marital status, income, etc.) and associated clinical/obstetric and gynecological implications. Bellieni [19] explains the paradox seen in western countries where fertility is socially discouraged by a mindset to exploit later in life, on expectations of gains of delayed parenthood, and the uninformed understanding of the associated risk of sterility provocation (infertility) as well as the greater gap between population. Our findings from pieces of literature and data analysis brought to the discussion, the association between our explanatory variables and ART use in the USA, as well as bringing to limelight the necessity to Xray the disproportionately high impact of racial/ethnic sociodemographic influence/implications on members of already underserved racial/ethnic minorities (e.g., Blacks, AIAN, Hispanic/Latino, NHOPI), underserved individuals of all racial/ethnic subgroup, as well as dwellers of rural America or communities. Right now, the future does not look promising for an improved equal maternal access to ART utilization and outcome. The prognosis as of now is even made worse, following the sudden new inclusion of COVID-19 (SARS-CoV-2) to the list, of it having a possible impact on fertility and assisted reproductive technologies [21]. All of this represent and constitute the palpable necessity, pressure, and demand for an available and accessible ART service and utilization for all women medically requiring it, regardless of maternal race or ethnicity.

The data presented in this study suggest that maternal race is strongly associated with an increased likelihood of having an ART treatment. This was also obvious when controlled for age, marital status, education, payment method, smoking status, and previous cesarean. Non-Hispanic White women are relatively higher than those of non-Hispanic Black, nonHispanic AIAN, non-Hispanic NHOPI, and Hispanic racial/ ethnic statuses in utilizing ART. This finding supports the result of other work. Humphries et al. [13] cited that race and ethnicity, especially Blacks, were strong predictors of poorer outcomes on ART treatment. A racial and ethnic difference in pregnancy rates following intrauterine insemination (ART) was also observed to be lower among American AIAN (prevalence PPR 0.60, 95\% CI 0.43-0.83) and Black (PPR $0.53,95 \%$ CI $0.44-0.63$ ) compared to White women in a study by Craig et al. [22] and Janitz et al. [17]. Also, a reduced ART service utilization was also observed for Hispanic women compared to non-Hispanic women as observed by Janitz et al. [17] in a binary racial/ethnic perspective. Dimitriadis et al. [23] concluded that race affects timely access to infertility care, diagnosis, and treatment cycle, having some racial groups waiting significantly longer prior to seeking evaluation. That of [24]; as cited in [3]) stated that some disparities are attributable by some degree to differences in access to care, economic, educational, as well as cultural factors. However, Shapiro et al. [3] concluded on two major findings: that utilization of ART is inversely related to fertility rates in the general population and that the lower utilization of ART 
among Black and Hispanic women is mainly due to lower demand rather than barriers to access. Dieke et al. [7] in a running commentary put forward that ART utilization was higher for women in states with an insurance mandate for ART treatment. Also stating that, the Asian or PI had the highest utilization in 2014, while the AIAN women having the lowest utilization rate. Nonetheless, it was concluded that though insurance mandates may increase access to infertility treatments, they are not sufficient to eliminate these disparities.

Our findings suggest a possible likelihood of confounders accounting for or constitute a compounded barrier to ART utilization, mostly through a combination of sociodemographic status and obstetrics and gynecological/ clinical conditions (explanatory variables) affecting access or indication for infertility treatment. Sociodemographic barriers likely heighten this phenomenon among those minority women who desire fertility services but are unable to utilize them due to lack of access, affordability, or social acceptance in their communities. Also, obstetrics and gynecological/ clinical conditions like maternal medical conditions (e.g., diabetes mellitus, hypertension), addictions (e.g., drugs/ smoking status), and/or previous surgery (e.g., cesarean section) may account for indications or contraindications for ART utilization. Likewise, one who is infected with an infectious disease like COVID 19, Zikka virus, Human immunodeficiency virus (HIV), Syphilis, Gonorrhea, Hepatitis, Chlamydia, etc., may present as a barrier.

[25]; as cited in [3]) put forward that a decline in fertility rates in the general population was observed after the year 2007, the period following the last economic recession. The declines in fertility rates were pronounced among underserved minorities, which has previously been attributed to the disproportionate effects of the recession on incomes of these minorities. On the other hand, Martin et al. (2015; as cited in [19]) added that fertility rates were seen to increase among women in their 30s and 40s, over the past three decades, as a result of more women delaying pregnancy to older reproductive ages. This is aside the increase in the number of same-sex couples and single individuals seeking parenthood, contributing to increased use of ART treatment generally and in particular among older women. According to Bellieni [19], scientific works of literature continue to be crystal clear on recommendations for a maternal less risky age range of childbearing to be between 20 and 30 years, regardless of the perceived benefit of delayed motherhood. However, the US data on delayed motherhood reflected adherence militating factors against this recommendation which summarily present as a strong and constant socioeconomic pressure on women.

Multiple prior studies reported that success rates of ART varied among different racial/ethnic groups [26], as cited in [3]). Thus, to knowledge, this study is the first to look at the association between a maternal race with a view to providing useful dimensions to counseling and ART treatment for an individual patient. This may help mitigate the various barriers that may be unevenly confounding to maternal race. The data used, therefore, add further credence to the previous hypothesis that the race/ethnicity of the patient may be a truly independent predictor of use and success with infertility treatment. We had also felt a sense of relief that in our little contribution to existing works of literature. We had, while finding an association (between maternal race as a predictor variable and ART use as outcome variable), primarily only looked at only one gender (female) and only one factor (female factor), but in reality, this has holistically touched on the primordial medically defined infertility treatment associated factors for any couple (above 50\%). Considering that, the following as shown on rmanetwork.com represent contributory makeup factors in the assessment of a patient with an infertility diagnosismalefactors (35\%), female factors (35\% contributory), a combination of male and female causation factors $(20 \%)$, and unexplained factors (10\%).

This study benefited from a nationwide report by ART clinics to SART of racial data in a significant percentage $(96.2 \%)$ of ART use. However, a respondent population of 67,554 out of $3,864,754$ live births on ART use posed a limitation to external validity. This is in conformity to the work of Quinn and Fujimoto [6] that assert that only a minority of the US population has access to treatment. Lack of external validity was found also to be a limitation in some other ART disparity studies with some having a low report of $39.6 \%$ [3]. The result of this study highlights the importance of reporting race when inputting demographic data of patients. This usually reduces the burden of accounting for missing data values and is therefore likely to be a major source of bias in this study. Maternal age, payment method, and educational status observed as strong confounders observed in this study should be addressed in future studies. Again, as an addendum, and of interest, future studies may also see the need to factor in the impact of the ongoing COVID-19 pandemic on reproductive health/ART utilization in America and globally.

Missing data values, in the study, were accounted for and clean up using standard allocated numbers. Likewise, confounding variables not meeting significance were eliminated additional analysis in the study. Thus, fertility treatment used, gonorrhea, syphilis, chlamydia, and pre-pregnancy diabetes covariates were not included in the regression analysis.

\section{Conclusion}

The study finds the utilization of ART in the USA to be associated with maternal race, suggesting that the odds are lower for racial/ethnic minorities to ART utilization. Future research in this area may, therefore, help to provide improved ART treatment access, irrespective of maternal race. 
Acknowledgements The authors acknowledge that this work arose from academic research carried out at the Central Michigan University, USA, public health data laboratory. The authors express their gratitude to the Central Michigan University department of public health (faculty and staff) and also to the Center for Disease Control and Prevention for making the dataset available for free online access. Gratitude also to the Master of Public Health Program director Professor Joseph Ntein Inungu (M.D., Dr.P.H) (Methods in Public Health Research) and to Livingstone Aduse-Poku (Biostatistics Graduate assistant) for their contributions.

Code availability CDC Code book User guide to the 2017 Natality Public use file was accessed from https://ftp.cdc.gov/pub/Health Statistics/NCHS/Dataset_Documentation/DVS/natality/UserGuide2017. pdf.

Authors' contributions Both authors have contributed equally to the work.

Data availability Data was access from the CDC free access file in SPSS format. Available from https://www.cdc.gov/nchs/data access/ vitalstatsonline.htm and https://ftp.cdc.gov/pub/Health_Statistics/NCHS/ Dataset_Documentation/DVS/natality/UserGuide2017.pdf.

\section{Declarations}

Ethics approval Not applicable.

Consent to participate Not applicable.

Consent for publication Both authors consent to publication.

Conflict of interest The authors declare no competing interests.

\section{References}

1. Inhorn MC, Patrizio P. Infertility around the globe: new thinking on gender, reproductive technologies and global movements in the 21st century. Hum Reprod Update. 2015;21(4):411-26. https:// doi.org/10.1093/humupd/dmv016.

2. Ombelet W. Global access to infertility care in developing countries: a case of human rights, equity and social justice. Facts Views Vision ObGyn. 2011;3(4):257-66.

3. Shapiro AJ, Darmon SK, Barad DH, Albertini DF, Gleicher N, Kushnir VA. Effect of race and ethnicity on utilization and outcomes of assisted reproductive technology in the USA. Reprod Biol Endocrinol. 2017;15(1):44. https://doi.org/10.1186/s12958017-0262-5.

4. de Mouzon J, Chambers GM, Zegers-Hochschild F, Mansour R, Ishihara $\mathrm{O}$, Banker $\mathrm{M}$, et al. International committee for monitoring assisted reproductive technologies world report: assisted reproductive technology 2012†. Human Reprod (Oxford, England). 2020;35(8):1900-13. https://doi.org/10.1093/humrep/deaa090.

5. Dyer S, Chambers GM, de Mouzon J, Nygren KG, ZegersHochschild F, Mansour R, et al. International committee for monitoring assisted reproductive technologies world report: assisted reproductive technology 2008, 2009 and 2010. Human Reprod (Oxford, England). 2016;31(7):1588-609. https://doi.org/10.1093/ humrep/dew082.

6. Quinn M, Fujimoto V. Racial and ethnic disparities in assisted reproductive technology access and outcomes. Fertil Steril.
2016;105(5):1119-23. https://doi.org/10.1016/j.fertnstert.2016.03. 007.

7. Dieke AC, Zhang Y, Kissin DM, Barfield WD, Boulet SL. Disparities in assisted reproductive technology utilization by race and ethnicity, United States, 2014: A Commentary. J Women's Health (2002). 2017;26(6):605-8. https://doi.org/10.1089/jwh. 2017.6467.

8. Armstrong A, Plowden TC. Ethnicity and assisted reproductive technologies. Clin Pract (London, England). 2012;9(6):651-8. https://doi.org/10.2217/cpr.12.65.

9. Centers for Disease control and prevention (CDC, 2019a). Reproductive health. Retrieved 2/20/2021 from https://www.cdc. gov/reproductivehealth/infertility/whitepaper-pg1.htm

10. Centers for Disease control and prevention (CDC,2019b). Assisted reproductive technology (ART). Retrieved 4/2/2020 from https:// www.cdc.gov/art/artdata/index.html

11. Adamson GD, de Mouzon J, Chambers G, Zegers-Hochschild F, Mansour R, Ishihara O, Banker M, Dyer S. Kupka M. International committee for monitoring assisted reproductive technology: world report on assisted reproductive technology, $2016 \mathrm{https}: / / \mathrm{www}$. icmartivf.org/reports-publications/

12. Nelson A. Unequal treatment: confronting racial and ethnic disparities in health care. J Natl Med Assoc. 2002;94(8):666-8.

13. Humphries LA, Chang O, Humm K, Sakkas D, Hacker MR. Influence of race and ethnicity on in vitro fertilization outcomes: systematic review. Am J Obstet Gynecol. 2016;214(2):212.e1212.e17. https://doi.org/10.1016/j.ajog.2015.09.002.

14. Seifer DB, Frazier LM, Grainger DA. Disparity in assisted reproductive technologies outcomes in black women compared with white women. Fertil Steril. 2008;90(5):1701-10. https://doi.org/ 10.1016/j.fertnstert.2007.08.024.

15. Feinberg EC, Larsen FW, Catherino WH, Zhang J, Armstrong AY. Comparison of assisted reproductive technology utilization and outcomes between Caucasian and African American patients in an equal-access-to-care setting. Fertil Steril. 2006;85(4):888-94. https://doi.org/10.1016/j.fertnstert.2005.10.028.

16. World Health Organization, WHO (2020). Sexual and reproductive health. Retrieved from https://www.who.int/reproductivehealth/ topics/infertility/definitions/en/ 12/4/2020

17. Janitz AE, Peck JD, Craig LB. Racial/ethnic differences in the utilization of infertility services: a focus on American Indian/Alaska natives. Matern Child Health J. 2019;23(1):10-8. https://doi.org/10. 1007/s10995-018-2586-y.

18. Rossen et al. (2016). Quarterly provisional estimates for selected birth indicators, 2014-Quarter 1, 2016 National Center for Health Statistics National Vital Statistics System, Vital Statistics Rapid Release Program.

19. Bellieni C. The best age for pregnancy and undue pressures. J Family Reprod Health. 2016;10(3):104-7 https://www.ncbi.nlm. nih.gov/pmc/articles/PMC5241353/; Accessed 4/5/2020.

20. Hamilton et al. (2018). Vital statistics rapid release. Births: provisional Data for 2017. Available from https://www.cdc.gov/nchs/ data/vsrr/report004.pdf

21. Blumenfeld Z. Possible impact of COVID-19 on fertility and assisted reproductive technologies. Fertil Steril. 2020;114(1):567. https://doi.org/10.1016/j.fertnstert.2020.05.023.

22. Craig LB, Weedin EA, Walker WD, Janitz AE, Hansen KR, Peck JD. Racial and ethnic differences in pregnancy rates following intrauterine insemination with a focus on American Indians. J Racial Ethn Health Disparities. 2018;5(5):1077-83. https://doi.org/10. 1007/s40615-017-0456-8.

23. Dimitriadis I, Batsis M, Petrozza JC, Souter I. Racial disparities in fertility care: an analysis of 4537 intrauterine insemination cycles. J Racial Ethn Health Disparities. 2017;4(2):169-77. https://doi.org/ 10.1007/s40615-016-0215-2. 
24. Smith JF, Eisenberg ML, Glidden D, Millstein SG, Cedars M, Walsh TJ, et al. Socioeconomic disparities in the use and success of fertility treatments: analysis of data from a prospective cohort in the United States. Fertil Steril. 2011;96(1):95-101. https://doi.org/ 10.1016/j.fertnstert.2011.04.054.

25. Sobotka T, Skirbekk V, Philipov D. Economic recession and fertility in the developed world. Popul Dev Rev. 2011;37(2):267-306. https://doi.org/10.1111/j.1728-4457.2011.00411.x.26.

26. Sharara FI, McClamrock HD. Differences in in vitro fertilization (IVF) outcome between white and black women in an inner-city, university-based IVF program. Fertil Steril. 2000;73(6):1170-3. https://doi.org/10.1016/s0015-0282(00)00524-0.

27. International Committee for Monitoring Assisted Reproductive Technology, Adamson GD, de Mouzon J, Lancaster P, Nygren $\mathrm{KG}$, Sullivan E, et al. World collaborative report on in vitro fertilization, 2000. Fertil Steril. 2006;85(6):1586-622. https://doi.org/ 10.1016/j.fertnstert.2006.01.011.

28. Mather M. Population Reference Bureau; World population data 2012; Available at http://www.prb.org/publications/datasheets/ 2012/world-population-data-sheet/fact-sheet-us-population.aspx; Accessed 11/2/16
29. rmanetwork,com,(2020). male-infertility-cases-and-statistics/. Retrieved from https://rmanetwork.com/blog/male-infertilitycases-and-statistics/ 2/25/2020

30. Seifer DB, Zackula R, Grainger DA, Society for assisted reproductive technology writing group report. Trends of racial disparities in assisted reproductive technology outcomes in black women compared with white women: Society for Assisted Reproductive Technology 1999 and 2000 vs. 2004-2006. Fertil Steril. 2010;93(2):626-35. https://doi.org/10.1016/j.fertnstert.2009.02. 084.

31. Wellons MF, Fujimoto VY, Baker VL, Barrington DS, Broomfield D, Catherino WH, et al. Race matters: a systematic review of racial/ ethnic disparity in Society for Assisted Reproductive Technology reported outcomes. Fertil Steril. 2012;98(2):406-9. https://doi.org/ 10.1016/j.fertnstert.2012.05.012.

Publisher's Note Springer Nature remains neutral with regard to jurisdictional claims in published maps and institutional affiliations. 